\title{
Percent of Total Hemoglobin
}

National Cancer Institute

\section{Source}

National Cancer Institute. Percent of Total Hemoglobin. NCI Thesaurus. Code C67220.

A unit for percentage measurement of any type or component of hemoglobin or its

derivative such as methemoglobin; carboxyhemoglobin; sulfhemoglobin, etc. evaluated as fraction of total hemoglobin. 